\title{
Theoretical bases and approaches to increase of investment attractiveness of a building complex
}

\author{
Vera Kudryavtseva ${ }^{1, *}$ \\ ${ }^{1}$ Irkutsk National Research Technical University, 664074, Irkutsk, Lermontova str., 83, Russia
}

\begin{abstract}
By its investment capacity and the range of social tissues to be solved, the construction industry is the most demanded by the state and society. The leading role of the construction complex is also determined by the fact that the final results can be achieved through analyzing the investment and construction complex in its regional aspect and implementing investment and construction programs and projects at the federal and regional levels. In this regard, the development of mechanisms to attract investment and ways to manage investment processes in the construction industry is the most important direction of the policy of the state and regional authorities. In this regard, it is required to clearly define and clarify the role of the regions in developing investment policies in order to increase the attractiveness of the regions' economy for investing in the longterm perspective, since investments are the stimulus for the economic development of industries. Investments in the construction complex should become the basis for bringing the industry to a new level of development, combining public, social, and commercial interests. The investment component helps to determine the volume, structure, and sources of financing for construction projects. Therefore, it is necessary to conduct an econometric assessment of the territories in terms of investment and construction volumes.
\end{abstract}

\section{Introduction}

The building complex of Russia is a developed sphere of production activity aimed at commissioning new objects of housing, as well as capital repair and reconstruction of epy existing buildings and structures.

On March 1, 2018, Russian President Vladimir Putin addressed an Annual Message to the Federal Assembly of the Russian Federation, during which he announced ambitious figures on the planned volume of commissioning square meters of housing for the future, up to 120 million square meters annually. At the same time, about 80 million square meters are introduced of 2017 in Russia, as of 2017 [9].

Undoubtedly, achieving the goals being set by the President (due to the high social importance and ever increasing demand for construction products) will largely depend on the economic and investment growth of the construction industry, which in turn is the main

*Corresponding author: kudravera@mail.ru 
catalyst for the development of any economic system of the country. World experience proves that investment and construction activity influences the investment climate of the country and regions from the point of view of increasing the gross regional product, tax revenues to regional budgets, providing housing for the population in the regions, and also determining the pace of social production development, etc.

\section{Materials and methods}

At present, the policy pursued by the Russian Government is aimed at developing the regional economy from the standpoint of the effective use of its own regional reserves. Therefore, it is necessary to consider the development of industries that are basic for the economy of the regions from the same position. With reference to the regional construction and building complex, it should be noted that the optimal combination of interests of the region, the city, investors, and construction industry enterprises is to be the top priority.

Investments to the construction complex should become the basis for bringing the industry to a new level of development; the investment component helps to determine the volume, structure, and sources of financing for construction companies.

At the same time, we should not forget that social and economic policies, the regional and local authorities' level of confidence, and the existence of a conflict-free environment for the functioning of business and regional authorities have a significant impact on the formation of a favorable and stable regional investment climate. In this regard, it is required to clearly define and clarify the role of the regions in the development of investment policies in order to increase the attractiveness of the region's economy for investment. The process of formation of an attractive investment climate in the region can be carried out by performing a series of successive actions, represented in large scale in Figure 1.

When choosing sectors for investment, it is necessary to focus on obtaining a possible multiplier effect in order to achieve a positive effect on investment in the selected industry, but it also should be leading to economic growth in the related industries of the region.

At the same time, the main investment attractiveness of the regions is, undoubtedly, the possession of the territory with basic advantages being attractive to investors, which, above all, includes rich reserves of natural resources, the capital city status, an advantageous geographical location, and the availability of transport communications [5].

For a fairly clear understanding of the current investment climate of the constituent entities of the Russian Federation, the Supervisory Board of the Agency for Strategic Initiatives decided to use the rating system of assessment, which would allow assessing the regions for creating conditions for doing business and attracting investments. Currently, an annual rating of the investment attractiveness of the regions of Russia is drawn up, according to which the regions are included in the groups depending on their potential and the level of risk. As of 2017, 83 subjects of the Russian Federation participated in the rating: "maximum potential - minimum risk" has 4 regions, "medium potential-minimum risk" - 6 regions, "reduced potential -minimum risk" - 10 regions, "insignificant potential - minimum risk" 0 regions, "high potential - moderate risk" - 1 region, "medium potential - moderate risk" 7 regions, "low potential - moderate risk" - 28 regions, "insignificant potential - moderate risk" - 13 regions, "maximum potential - high risk" and "medium potential - high risk" - 0 regions, "reduced potential - high risk" - 3 regions, "insignificant potential - high risk" - 9 regions", "low potential - extreme risk" - 2 regions of the Russian Federation [11].

Based on this rating, we can say that many regions of Russia in 2017 began to enter precrisis indicators: investment activity and investment attractiveness began to grow. 
Subjects of formation of the region's investment climate: federal, regional and local authorities; participants in investment activities

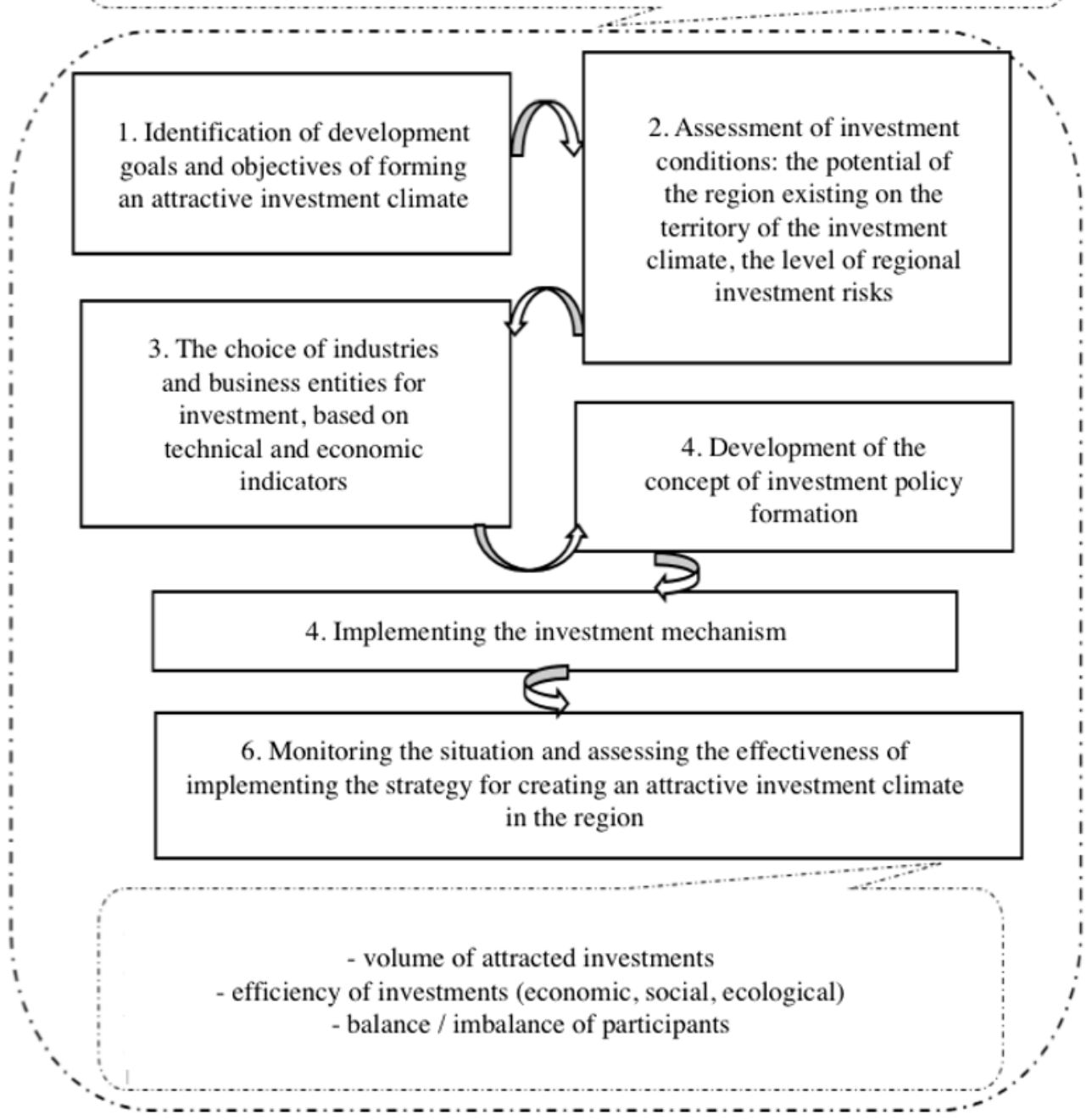

Fig. 1. Process of formation of the regional investment climate.

The construction industry in 2016 accounted for about 5.2\% of the Russia's total GDP. Therefore, the issue of attracting investment in construction and creating effective mechanisms for this taking into account the interests of all market participants at regional levels is relevant (Fig. 2). 


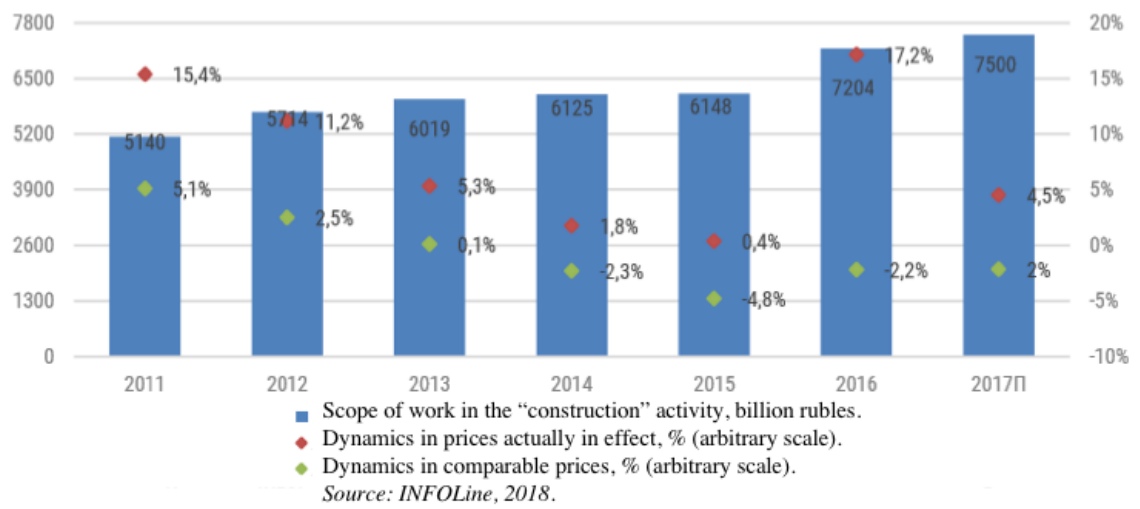

Fig. 2. Indicators of investment and construction activity in the Russian Federation by years.

As of 2012, most of the state investments in fixed assets accounted for transport and communications, about $40 \%$ (Figure 3).

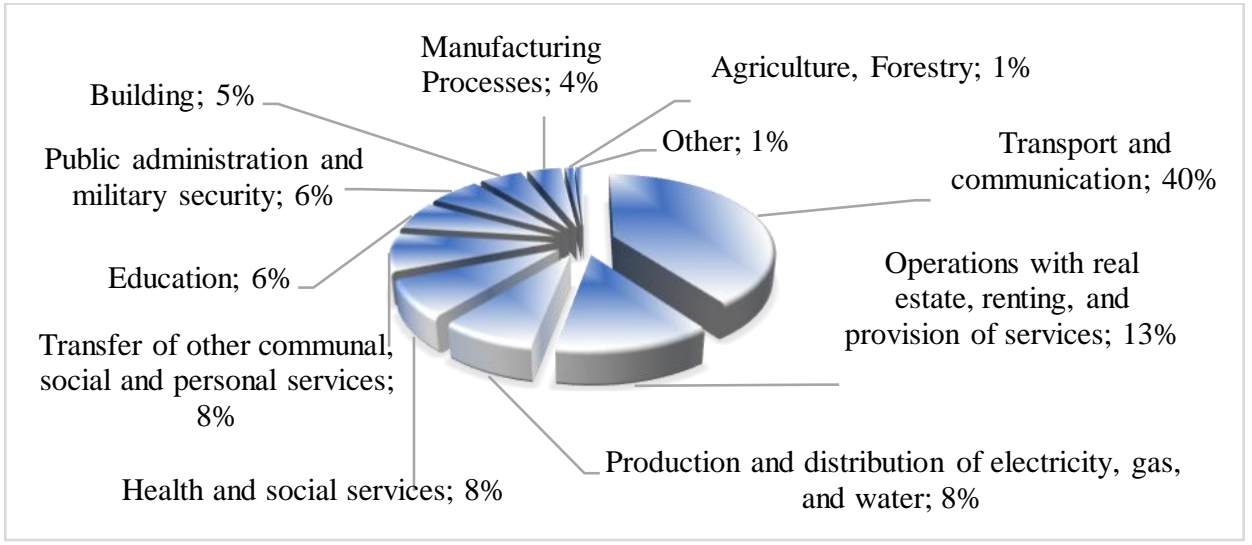

Fig. 3. Distribution of state investments by types of economic activity (2012).

The forecasted structure of investment in fixed assets by industry, outlined in the Concept of Long-Term Social and Economic Development of the Russian Federation for the period up to 2020, is shown in Fig. 4.

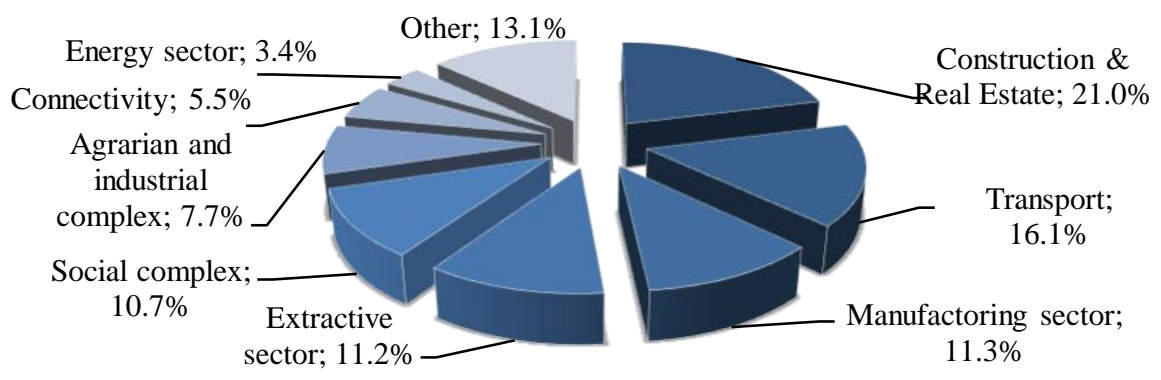

Fig. 4. The forecast structure of the distribution of the total volume of investment in fixed assets in Russia in 2020 in terms of main industries, \%. 
According to the forecast data, it is expected by 2020 that the largest increase in capital investments will be in such sectors as construction and real estate, transport, manufacturing and extractive industries. Those investments in construction of buildings and industrial and commercial buildings ( $21 \%$ of the total volume) prevail in the structure of investments, followed by investments in transport, machinery, and equipment $(16.1 \%, 11.3 \%$, and $11.2 \%$, respectively) [10].

These industries are the most attractive for investments due to the influence of various factors, such as high market growth rates, high added value of products, and relatively low risks for investment, if compared to other industries, etc.

Most of the investments, both foreign and domestic, are concentrated in regions with high economic potential and low or moderate entrepreneurial risk. This is especially true for foreign investors.

At the same time, the construction sector is one of the largest growing and dynamic sectors in the world economy: about 10 trillion dollars a year is spent on buildings, infrastructure, and industrial facilities, and this amount, according to European forecasts, will increase to $\$ 14$ trillion in 2025 . Based on this, the future and prospects for the construction industry in Europe look large and promising. In order to achieve the set goals, the Action Plan "Construction 2020" was developed in 2013 to ensure that the industry becomes more competitive and ensures sustainable growth in the short and long term. The Action Plan "Construction 2020" is a comprehensive plan that outlines the strategy of "sustainable competitiveness of the construction sector and its enterprises," which identifies the key factors of competitiveness and efficiency.

The plan includes 5 key objectives:

1) attracting investments into the construction of new buildings;

2) human capital;

3) resource efficiency;

4) improving the internal construction market;

5) maintaining competitiveness in the global industry $[14,15]$.

The forecast of the European construction market has always been a challenge for analysts because of the many different players in the region. There are large territorial and significant differences in the industry itself. In general, the European construction industry is divided into two major sectors: large players are engaged in construction, such as facilities, industrial complexes, civilian housing units, as well as a large number of firms are engaged in specialized construction work, such as commissioning, electrical and plumbing work. The first group, as a rule, has productivity of $20-40 \%$ higher than the second one.

The restoration of the European economy contributed to the growth of construction in Europe itself. In 2016, the volume of construction increased by $2.5 \%$, which is $0.5 \%$ higher than expected. According to Eurostat, construction activity among small and medium-sized enterprises increased in Slovenia (by 27.8\%), Hungary (22.0\%), Sweden (19.8\%), and the largest decline occurred in Romania (-18.4\%), Italy (-4.6\%), and the United Kingdom (3.4\%). In France, the construction of small and medium-sized enterprises in the first quarter of 2017 increased by $1.5 \%$, confirming that the recovery path began in 2016 [12].

In Sweden, a set of measures to stimulate the economy supports the development of housing construction: there is a potential investment of 95 billion euros to build additional 295,000 new apartments until 2030. 
Investments in France and Austria also focus on the real estate sector: for example, in Austria, it is expected that at least 30,000 additional houses will be introduced by 2020 . In France, sales of apartments increased by $18 \%$ in 2016 . Despite the positive data, there is still room for further investment. Total investment in the euro area still does not reach the level before the financial crisis, although the European construction market entered the recovery phase [13].

In the current situation, both in the Russian and European economy, the rapidly changing external environment, as well as the volume of financial resources, both own and borrowed, the investor needs to select and execute an estimate of investment intentions for the implementation of a particular investment project:

1) to consider the attractiveness of the real estate object from the position of location, degree of readiness, profitability, availability of documents, etc.;

2) to analyze the attractiveness of the surrounding area from the point of view of the development of infrastructure,

3) to study the attractiveness of the facility at the regional level from the standpoint of investment attractiveness: the level of economic security and financial policy, the situation in the regional real estate market [4].

Since the ultimate goal of the investment and construction complex is a ready-made real estate object, the relationships of the participants in the investment and construction complex are in the receipt and distribution of economic benefits from the creation, implementation, and operation of the finished real estate on the market. The major basic processes in investment and construction activities include the following chain: selection and evaluation of investment intentions - pre-project preparation/design - investments construction/reconstruction - operation/extraction of profit, benefits (return on investment).

The analysis showed that the construction industry is characterized by a positive dynamics of investment, which determines the growth of investment activity in the future, because the practice shows that the market for investment resources and the construction market are closely interrelated and interdependent.

At the same time, the achievement of Russia's economic level of foreign countries is possible only in the condition of a large-scale increase in investment activity, an increase in the volume of capital investments in new construction, reconstruction and technical reequipment of existing fixed assets of enterprises, with a faster development of the production potential of the construction industry and its material and technical base [16, 17].

\section{Results}

At present, the Russian authorities devote special attention to creating a favorable investment environment in the constituent entities of the Russian Federation, which is necessary for developing the key industries and determining their level of influence on economic growth of the country and regions in the context of differentiation of the Russia's economic space.

Construction, as a basic branch of the national economy, is an important link in the economy of any region. The construction industry needs the formation in the regions of an investment policy that would ensure sufficient supply of the entire investment and construction process and investment flows in order to satisfy the interests of investors.

\section{Discussion}

Factors of investment attractiveness of the region are one of the key factors when choosing sectors for investment and development of investment policy aimed at increasing economic growth. 
However, it should be remembered that the construction industry has a number of features on the basis of which Russian scholars $[1,2,3,7,8]$ determine a range of factors that reduce its attractiveness for investors. The main factors include: commodity dependence; presence of risks caused by external and internal environment; duration of the investment project implementation cycle in the construction industry; limited science-intensive products on the market; the complexity of erecting unique buildings and structures; the lack of a unified methodology for assessing the effectiveness of the investments received.

In general, the choice of investment project selection methods will be based on specific information about the investment object, factors depending on the external and internal environment, on the project's compliance with the strategic goals and interests of the region. Thus, the use of modeling methods when making decisions on investing in the areas of activity in the investment and construction complex is an actual and expedient tool at this stage.

At the same time, it should be noted that the effectiveness of this method depends on the qualification of the specialists who formulate the criterion, as well as the completeness of information on the social and economic situation in the region and the clarity of the definition of priority objectives, and the evaluation of performance criteria. The choice of formal characteristics is laborious, and it does not allow to evaluate the influence of many factors.

\section{Conclusion}

In contemporary conditions of development, the investment and construction complex plays an important role in increasing the GDP of the Russian Federation. And an increase in the growth rates, strengthening of positions in the economy, and the creation of a competitive construction industry today are an urgent and priority national economic goal. Therefore, the issue of the quality of regulation and investment is so important, as well as the creation of effective mechanisms for this, taking into account the interests of all participants in the construction market.

\section{References}

1. A. N. Asaul, Investment attractiveness of the region (SPbGASU, St. Petersburg, 2008)

2. A. N. Asaul, Successes of Modern Natural Science, 2, 124-127 (2011)

3. P. G. Grabovy, Real Estate: Economics, Management, 2, 11-13 (2015)

4. V. A. Kudryavtseva, Proceedings of the Practical Conf. "Construction: Forming the Environment of Life, 652-654 (2017)

5. V. A. Kudryavtseva, Proceedings of High Schools. Investments. Construction. Real Estate, 1 (12), 49-54 (2015)

6. L. G. Kochegarova, Management of regional investment processes (Publishing house of the South Ural State University, Chelyabinsk, 2015)

7. Yu. M. Farukshina, Young Scientist, 421-423, (2014)

8. B. B. Khrustalev, V. N. Gorbunov, A. V. Orgin, Scientific aspects of formation and development of effective zones of activity of a building complex (PGUAS Publishing House, Penza, 2007)

9. Message of the President of the Russian Federation to the Federal Assembly of 01.03.2018 (Consultant Plus, Moscow, 2018)

10. Strategy of innovative development of the construction industry of the Russian Federation until 2030 (Consultant Plus, Moscow, 2015) 
11. Results of the 5th annual rating of the investment attractiveness of Russian regions (Moscow, 2017)

12. Annual report European Builders Confederation 2016-2017, Performance and Trends of the Construction Sector, 28, 11, (2017)

13. European construction companies in 2017 (https://buildingradar.com/constructionblog/european-construction-companies, Brussels, 2018)

14. The European construction market forecast from 2015 to 2020 (https://buildingradar.com/construction-blog/european-construction-market-forecast, Brussels, 2018)

15. G. Katsarakis, Eurocodes - Design of Steel Structures, 10, (2014)

16. Y. V. Ragulina, A. V. Bogoviz, A. N. Alekseev, Advances in Intelligent Systems and Computing, 622, 568-573 (2018)

17. A. Kudryavtseva, Proceedings of Universities: Investment. Construction. Real Estate, 1(20), 45-52 (2017) 